\title{
Investigation of Dynamic Mechanical Properties of Coal after Freeze-Thaw Cyclic Conditions
}

\author{
Shuang Gong $\mathbb{D}^{1,2,3}$ Wen Wang $\mathbb{D}^{1,3}$ Furui Xi $\mathbb{D}^{4,5}$ and Wenlong Shen $\mathbb{D}^{1,3}$ \\ ${ }^{1}$ School of Energy Science and Engineering, Henan Polytechnic University, Jiaozuo 454000, China \\ ${ }^{2}$ Henan Key Laboratory for Green and Efficient Mining \& Comprehensive Utilization of Mineral Resources, Jiaozuo 454000, China \\ ${ }^{3}$ Collaborative Innovation Center of Coal Work Safety, Henan Province, Jiaozuo 454000, China \\ ${ }^{4}$ China Institute of Geo-Environment Monitoring, Beijing 100081, China \\ ${ }^{5}$ Key Laboratory of Mine Ecological Effects and Systematic Restoration, Ministry of Nature Resource, Beijing 100081, China
}

Correspondence should be addressed to Wen Wang; wwang306@foxmail.com and Furui Xi; xifurui@mail.cgs.gov.cn

Received 9 September 2021; Accepted 7 October 2021; Published 28 October 2021

Academic Editor: Yu Wang

Copyright (C) 2021 Shuang Gong et al. This is an open access article distributed under the Creative Commons Attribution License, which permits unrestricted use, distribution, and reproduction in any medium, provided the original work is properly cited.

\begin{abstract}
Due to the extensive excavation of the mine pit, a special frozen rock slope is formed, which transforms the permafrost (coal rock) of certain thickness in the frozen state to the melting state. To evaluate the dynamic mechanical properties and deformation characteristics of coal under cyclic freeze-thaw conditions, freeze-thaw experiments with different cycle times were conducted. And the mechanical properties of coal under quasistatic and dynamic conditions were investigated by using GCTS multifunctional rock mechanic experimental apparatus and SHPB dynamic loading apparatus, respectively. The results show that with the increase of freeze-thawing times, mass of both water-saturated and dried coal samples gradually decreased, the postpeak becomes gentler, and the specimens show ductile damage characteristics. The damage of the coal samples changed more after 30 freeze-thaw cycles, when deterioration of the coal samples was highest. The elastic modulus of the coal sample after freeze-thawing decreases continuously with the increase of the number of freeze-thaw cycles, and its trend decreases approximately linearly. Dynamic compressive strength of the coal samples decreases after freeze-thaw cycles, and this trend is consistent with the quasistatic loading conditions.
\end{abstract}

\section{Introduction}

With the decreasing amount of coal resources in China and the increasing energy demand year by year, several cities with depleted coal resources have emerged in the Middle East [1-3]. Coal resource development has been gradually extended to the northwest planning area, where several large open-pit coal mines are located in the high-altitude perennial permafrost zone. Due to the extensive excavation of the mine pit, a special frozen rock slope is formed, which transforms the permafrost (coal rock) of certain thickness in the frozen state to the melting state. With the change of temperature and the two-state cycle of freezing and melting, the nature of coal rock medium is also changing, thus, mak- ing the frozen rock slope of open pit mine in high altitude permafrost area a special slope. The special characteristics of high-altitude areas are mainly manifested in two aspects: climatic conditions and stratigraphic conditions [4-6]. Wang et al. [7] investigate the fatigue mechanical characteristics of marble having different interbed orientation subjected to multilevel constant-amplitude (MLCA) cyclic loads. The experimental results reveal that the deformation, strength, lifetime, damping characteristics, and energy release and dissipation are all impacted by the interbed structure. The rock structural deterioration and damage accumulation were investigated as well as the stimulated natural fracture pattern. Results show the frost heaving force acted on natural fracture results in the rock volumetric 


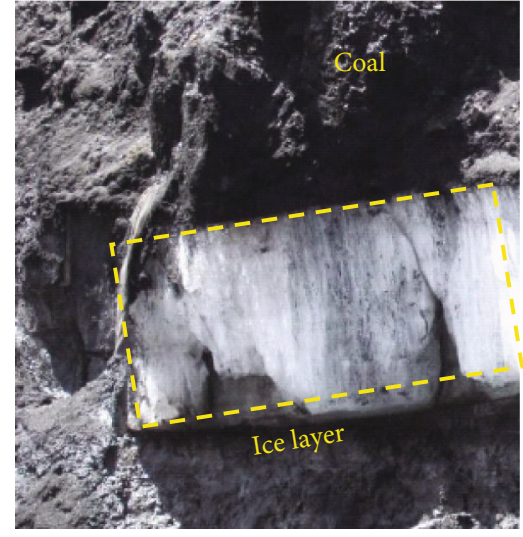

(a)

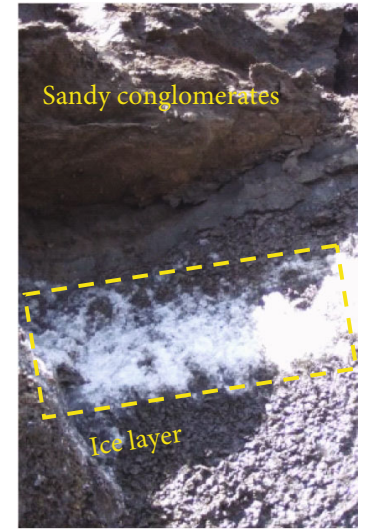

(b)

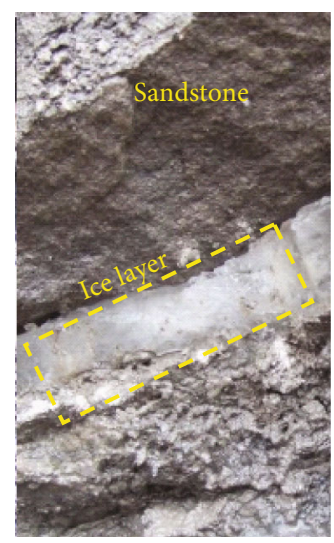

(c)

FIgURe 1: Picture of ice layer in coal and rock mass of open pit slope.

changes [8]. A typical open pit mine in Qinghai Province is taken as the study site, and the ice layer in its coal rock mass is shown in Figure 1.

The altitude of this area is above $4000 \mathrm{~m}$. Spatially, it belongs to the high-altitude cold area of Qinghai-Tibet Plateau, and the surface water system is more developed. The annual and monthly temperature changes in the area are shown in Figure 2, from which it can be seen that the coalfield area has a large temperature difference and has the distinctive characteristics of an alpine area. In the high-altitude zone, due to the peculiarities of the natural environment, as shown in Figure 2, the slope is in the alternating state of above-zero and below-zero temperature for many years and months, and the surface water-saturated rock and structural surface of the slope are in the cyclic and repeated freezing and melting state. Due to the direct influence of atmospheric environment, the rock properties of frozen rock slopes of open pit mines in high altitude areas undergo unstable changes related to temperature and moisture, which is the essential difference between these slopes and those of conventional open pit mines.

The analysis of the evolution law of slope stability based on the changes of ambient temperature and moisture can more accurately describe the safety status and change trend of the slopes of open pit coal mines in high altitude areas. Appropriate safety protection can be carried out accordingly to improve the safety of mining operations. There is a freezing period of more than half a year, the temperature starts to rise gradually in April, and the stratum starts to melt gradually. The high-temperature period is basically from June to September, during which the ground surface is in a state of ablation, and the strata gradually freeze from October. In addition, during most months, there is often a cycle of above- and below-zero temperatures within a day. The surface will undergo a phase cycle of melting and freezing. In the actual production process of open pit coal mine, there are external forces such as blasting, earthquake, excavation, and mechanical vibration. The slope structure of coal rock mass is disturbed by different degrees of dynamic loads, and there is a safety risk of instability [9-11]. The dynamic loading mode of coal rock under freeze-thaw damage conditions is a common phenomenon in current engineering practice. Therefore, the study of rock mechanical properties of freeze-thaw damaged rocks under dynamic loading form has important guiding significance and practical engineering application value, which can provide a reliable theoretical basis for the construction design and scheme optimization of related projects.

Many scholars have made a series of achievements in the research of rock freezing and thawing and introduced a series of modern means. Yang et al. [12] proposed the development direction of rock mass freeze-thaw multiscale 


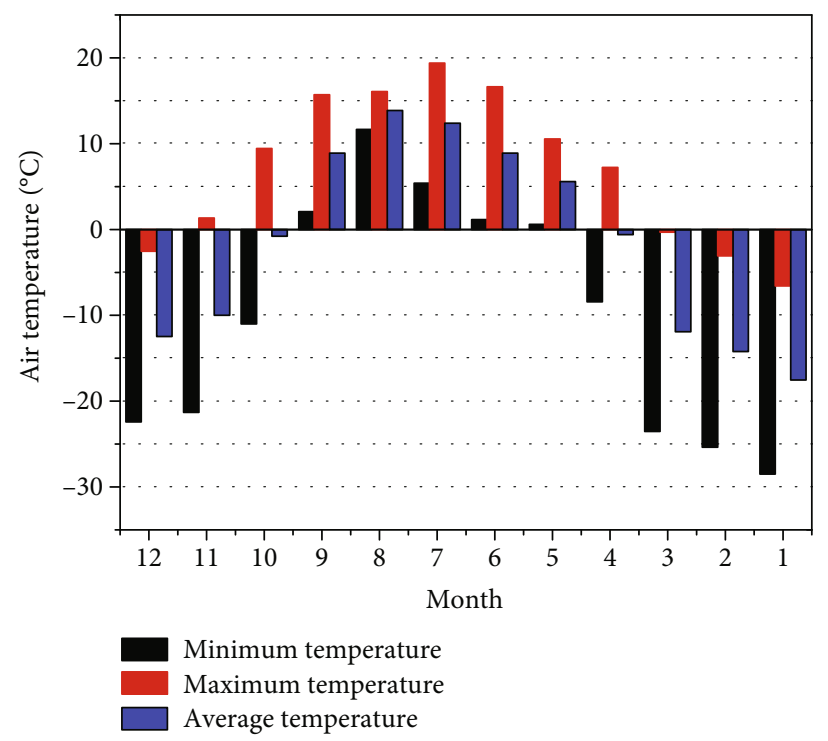

(a)

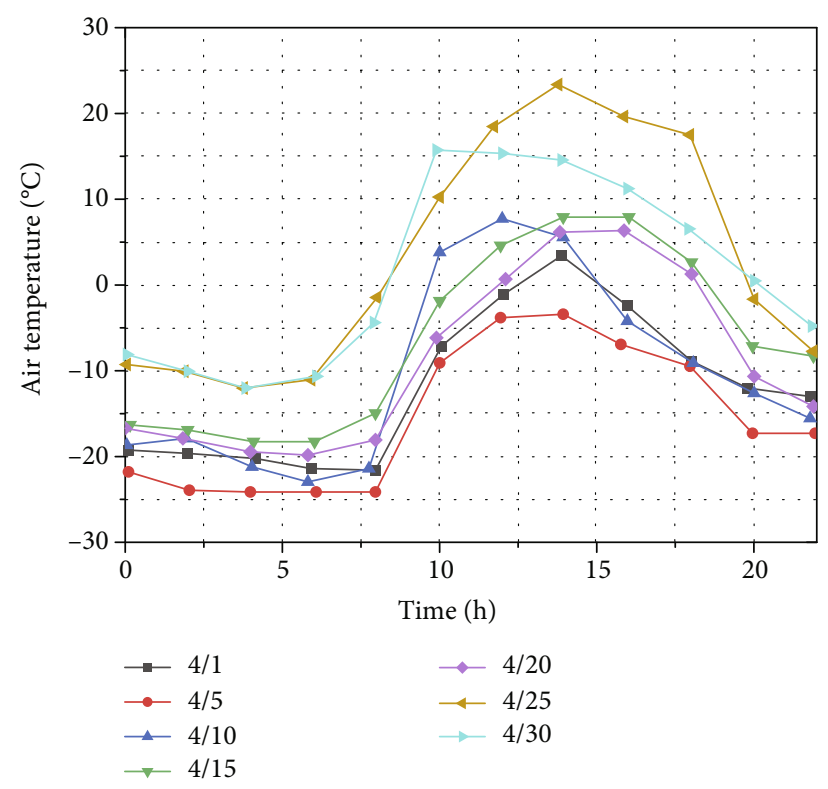

(b)

Figure 2: Variation law of annual and daily temperature in coalfield area where open-pit coal mine is located. (a) Variation law of temperature over the years. (b) Variation law of calendar day temperature.

damage identification and evaluation mechanism and preliminarily discussed the microfine macrocross-scale cognitive idea of rock mass damage induced by freeze-thaw. Xu et al. [13] established a theoretical model of rock freezethaw deterioration of sandstone samples selected from the slope of open-pit mine. Wen et al. [14] preliminarily discussed the engineering application of freezing and thawing rock test results. İsmailİnce [15] analyzed the microscopic images of frozen and thawed rocks. Fener [16] analyzed the porosity characteristic of rock and studied the polarizing microscope image. Khanlari and Abdilor and Park et al. [17, 18] analyzed the rock freeze-thaw damage qualitatively and quantitatively from the microscopic point of view by means of electron microscope scanning and CT scanning. Therefore, scholars generally pay attention to the laboratory tests of mechanical properties and freezing and thawing mechanism of freeze-thaw rocks.

The dynamic and static combined loading characteristics of frozen and thawed rock have developed rapidly in recent years. However, the research in this field is still in the development stage, and there is some relevant literature for reference. Wang et al. $[19,20]$ used the automatic freezing and thawing cycle system to freeze and thaw the red sandstone sample, and the visible cracks were generated after the rock freezing and thawing. Dynamic mechanical properties of rock sample before and after freezing and thawing were studied by using a one-dimensional SHPB device with a diameter of $100 \mathrm{~mm}$, and the changes of the physical, static, and dynamic mechanical properties of the rock sample were analyzed. Zhou et al. [21] studied the changes of saturated porosity of rocks with different freeze-thaw cycles and made a subtle study by NMR technology. Wen et al. [22] conducted multiple freezing and thawing of granite porphyry samples, used one-dimensional SHPB experimental device for impact loading, and analyzed the dynamic strength of rock samples with different freezing and thawing times under the same strain rate in combination with numerical simulation software.

At present, the design and protection theories of frozen rock slopes of open pit coal mines in high altitude areas are based on the theories of conventional open pit slopes. The research on the evolution of slope stability under the influence of multiple factors is carried out in a targeted manner, especially the mechanical characteristics of coal rock under the disturbance of external dynamic load after freeze-thaw cycles. The conclusion can complement the theory of stability of frozen rock slopes in open pit mines and provide theoretical basis for sound slope design and safety protection in special areas. Therefore, it is of great theoretical significance to study the mechanical properties and deformation characteristics of coal rock masses in open pit coal mines in cold regions under the combined effects of freeze-thaw cycles and dynamic load disturbances to ensure the safe mining of open pit coal mines.

\section{Test Preparation}

2.1. Sample Preparation. The coal samples were taken from Muli mine field, an open pit mine in the cold area of Northwest China. Muli mining area is located in northwest China, with mountains and valleys. Table 1 shows the industrial analysis parameters of coal samples. Calorific value of the coal sample is $6850 \mathrm{cal} / \mathrm{g}$, the moisture content is $2.065 \%$, the air-dry ash is 15.9 , the dry basis ash is 6.083 , and the vitrinite reflectance is 3.16 . Table 2 shows the chemical composition. Nitrogen value is $0.795 \%$, the carbon is $78.032 \%$, the hydrogen is $2.851 \%$, the oxygen is $1.169 \%$, the sulphur is $0.43 \%$, and the other elements are 16.723 . The coal 
TABLE 1: Industrial analysis parameters of coal samples.

\begin{tabular}{lcccc}
\hline $\begin{array}{l}\text { Calorific value } \\
(\mathrm{cal} / \mathrm{g})\end{array}$ & $\begin{array}{c}\text { Moisture } \\
(\%)\end{array}$ & $\begin{array}{c}\text { Air dry } \\
\text { ash }\end{array}$ & $\begin{array}{c}\text { Dry basis } \\
\text { ash }\end{array}$ & $\begin{array}{c}\text { Vitrinite } \\
\text { reflectance }\end{array}$ \\
\hline 6850 & 2.065 & 15.9 & 6.083 & 3.16 \\
\hline
\end{tabular}

TABLe 2: Chemical composition of coal sample.

\begin{tabular}{lccccc}
\hline $\begin{array}{l}\text { Nitrogen } \\
(\%)\end{array}$ & $\begin{array}{c}\text { Carbon } \\
(\%)\end{array}$ & $\begin{array}{c}\text { Hydrogen } \\
(\%)\end{array}$ & $\begin{array}{c}\text { Oxygen } \\
(\%)\end{array}$ & $\begin{array}{c}\text { Sulphur } \\
(\%)\end{array}$ & $\begin{array}{c}\text { Other } \\
\text { elements } \\
(\%)\end{array}$ \\
\hline 0.795 & 78.032 & 2.851 & 1.169 & 0.43 & 16.723 \\
\hline
\end{tabular}

specimen is processed into a cylinder. Accuracy of specimen meets the requirements of the rock dynamic properties test procedure (T/CSRME001-2019). Ensure that the error of flatness of both ends of the specimen is not more than $0.05 \mathrm{~mm}$. Loading displacement was set to $0.02 \mathrm{~mm} / \mathrm{s}$ for the quasistatic condition, and the impact air pressure was set to $0.4 \mathrm{MPa}$ for the dynamic impact test. Four freezethaw cycles $(0,10,20$, and 30$)$ were set, and three coal rock specimens were set for each condition. The selected specimens were numbered.

The selected and numbered specimens were put into the water-saturated dish, and distilled water was injected into the water-saturated dish to submerge the specimens. The water-filled dish is continuously pumped with $0.1 \mathrm{MPa}$ pressure for $4 \mathrm{~h}$ until no bubble overflows on the surface of the specimen and then soaked for more than $24 \mathrm{~h}$ to obtain the water-saturated specimen. The saturated specimen is put into the automatic low temperature freeze-thaw test chamber (temperature accuracy: $\pm 0.5^{\circ} \mathrm{C}$; temperature range: $50^{\circ} \mathrm{C} \sim-40^{\circ} \mathrm{C}$ ) for freeze-thaw cycle test. Considering the historical minimum temperature of the sampling site and referring to the relevant specifications, the temperature was set to $-20^{\circ} \mathrm{C} \sim 20^{\circ} \mathrm{C}$. Each freeze-thaw cycle lasted $720 \mathrm{~min}$, as shown in Figure 3.

2.2. Experimental System. The specimens that reached the freeze-thaw limited number of times were subjected to quasistatic and dynamic uniaxial compression tests, and the instruments used were the GCTS rock mechanics loading device and the $\Phi 50 \mathrm{~mm}$ SHPB system, respectively, as shown in Figure 4.

\section{Results and Discussion}

3.1. Mechanical Properties of Coal after Freeze-Thaw Cycle. No macroscopic cracks were observed in the coal samples throughout the freeze-thawing process, and all of the coal samples showed surface particle exfoliation. The drying and water-saturated masses of the coal samples at different freeze-thaw times $(0,10,20$, and 30) are shown in Figure 5. With the increase of freeze-thawing times, the mass of both water-saturated and dried coal samples gradually decreased, and the decreasing trend was basically consistent. However, there is a slight difference in the degree of change

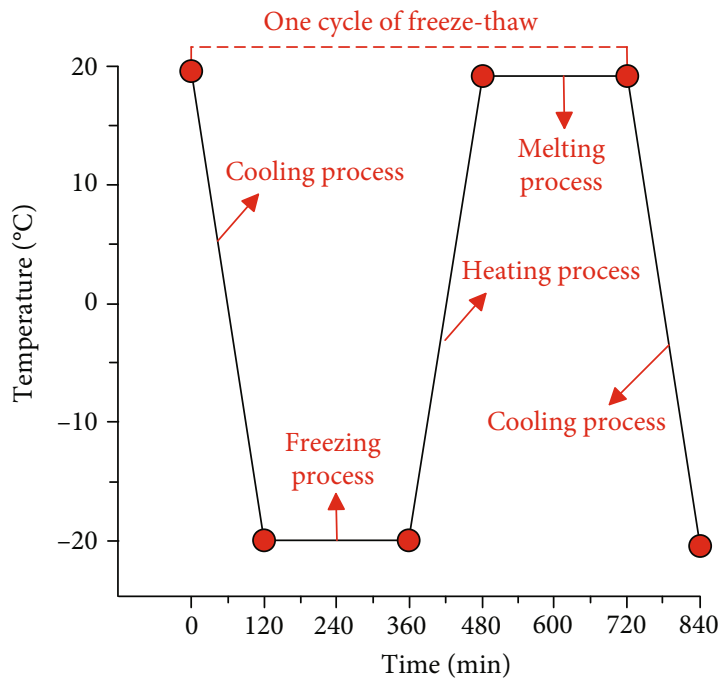

FIgURE 3: Temperature-time curve of freeze-thaw cycle.

between the two, which is due to the change in the degree of open fracture penetration caused by the formation and change of internal debris in the rock after different freezethawing times. Compared with the nonfreeze-thawed rock samples, the quality of the water-saturated rock samples decreased by $8.33 \%$ after 10 freeze-thaw cycles, $18.33 \%$ after 20 freeze-thaw cycles, and $33.33 \%$ after 30 freeze-thaw cycles. After each freeze-thaw cycle, the mass of rock samples decreased significantly, and the surface layer further spalling occurred significantly.

Typical stress-strain curves for coal samples subjected to $0,10,20$, and 30 freeze-thaw cycles are shown in Figure 6. The peak strength of unfrozen-thawed specimens is the largest. With the increase of the number of freeze-thawing, the postpeak becomes gentler and specimens show ductile damage characteristics. The stress-strain curves before and after freeze-thawing can be divided into four stages, i.e., compression-density stage, elastic stage, crack development stage, and damage stage. With the increase of the number of freeze-thawing, compressive phase was significantly extended. In particular, the compressive stage of freezethawed samples with 20 times of freeze-thawing increased significantly compared with those without freeze-thawing. This indicates that the first 20 freeze-thaw cycles led to the significant development of microfractures inside the specimens.

The longitudinal wave velocity of rock is affected by various factors such as mineral composition, cement and condition, and porosity and structural form. The wave velocities of saturated rock samples and dried rock samples all decrease gradually with the increase of freeze-thawing times, mainly because the pores in the rock samples keep increasing with the increase of freeze-thawing times. The denseness of the rock sample decreases, and the voids are filled with water or air, which leads to the decrease of the longitudinal wave velocity after freeze-thawing because the velocity of longitudinal waves in water or air is much smaller than the propagation velocity in rock. Since the open pores of the rock sample are filled with water after the sample is full of 


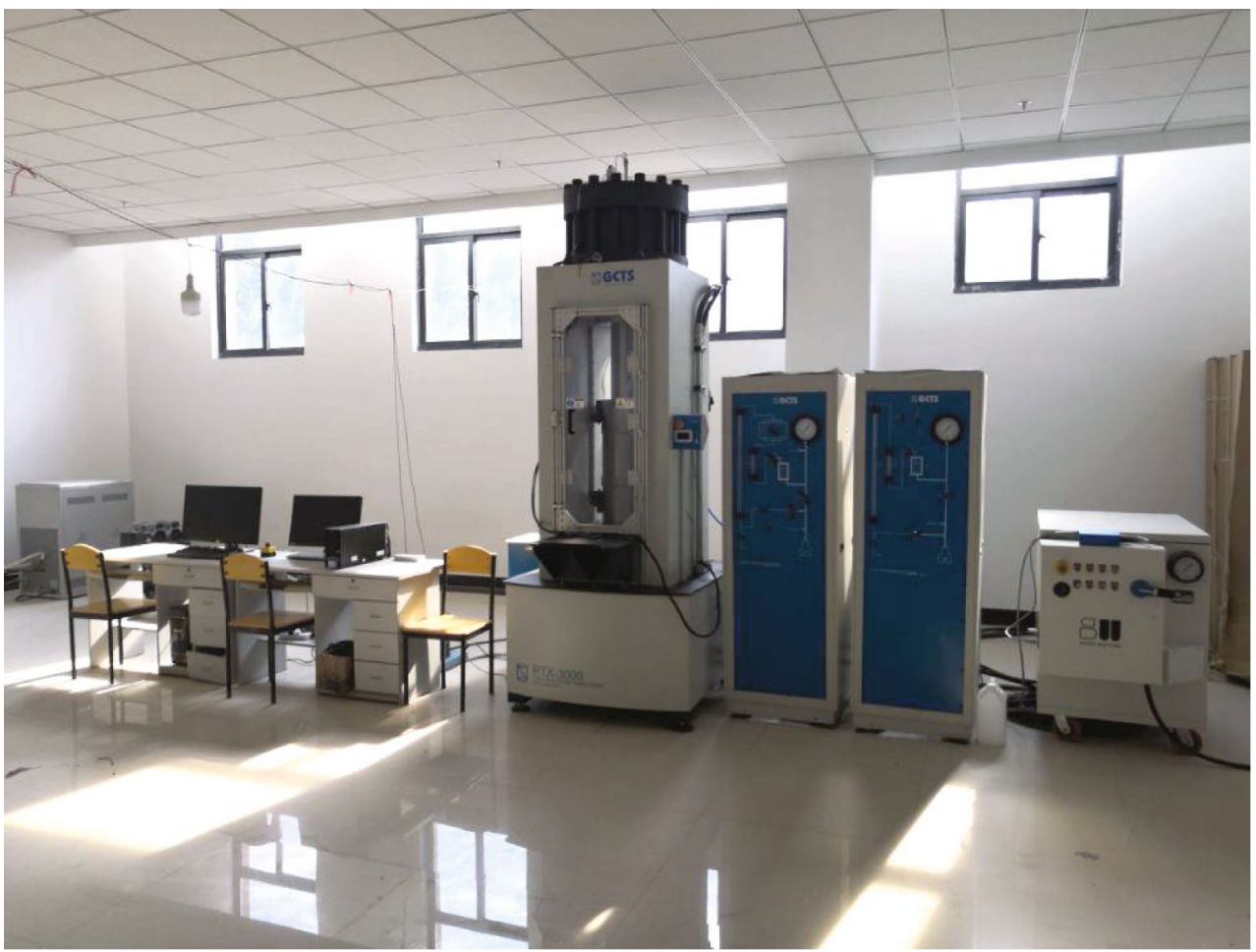

(a)

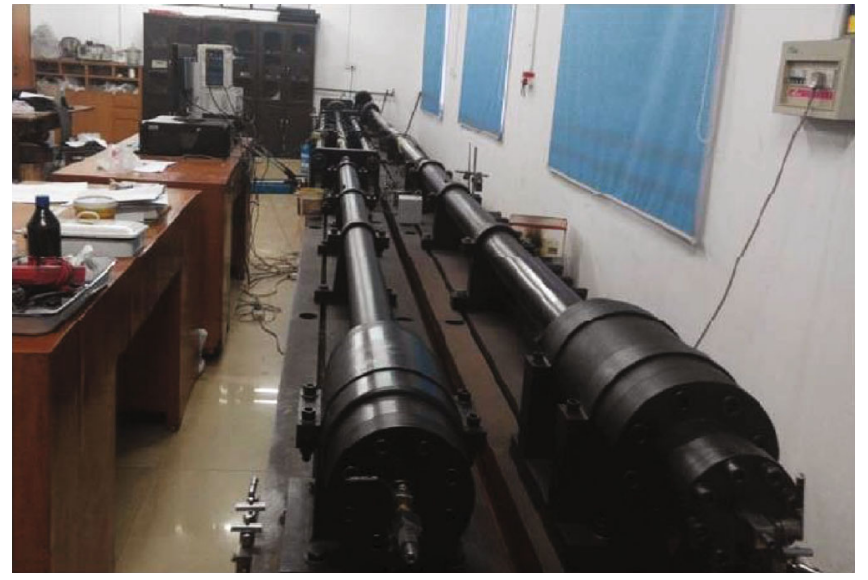

(b)

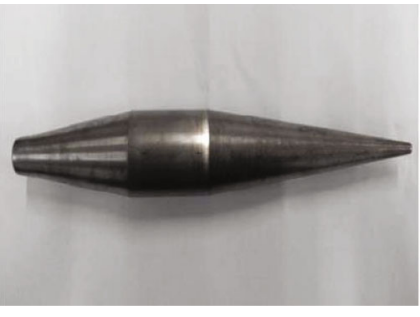

(c)

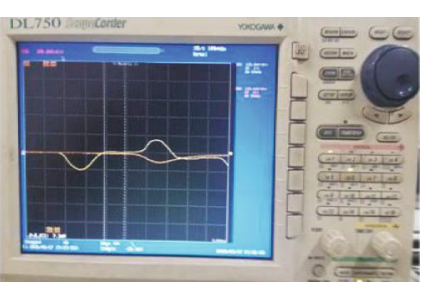

(d)

FIgURE 4: Continued. 


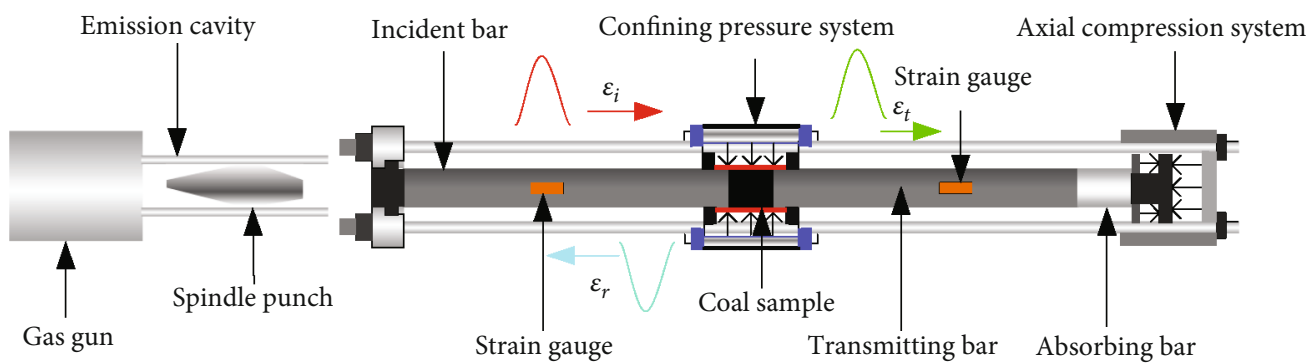

(e)

FIGURE 4: Rock mechanics loading device with different strain rate. (a) GCTS loading device. (b) Hopkinson bar dynamic loading device. (c) Spindle punch. (d) Sine wave waveform recording instrument. (e) Hopkinson bar.

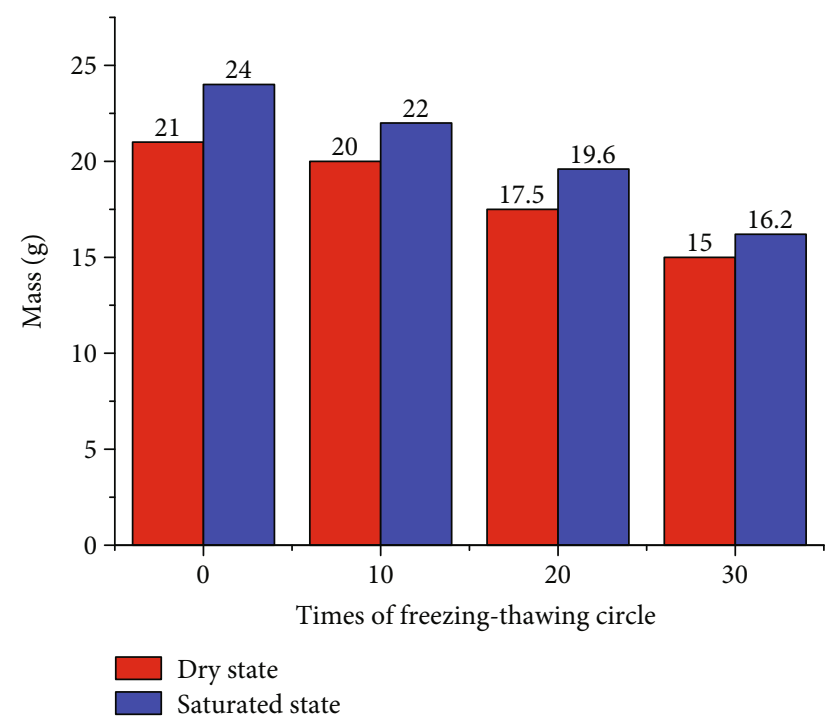

FIGURE 5: Histogram of the average mass of coal samples versus the number of freeze-thaws.

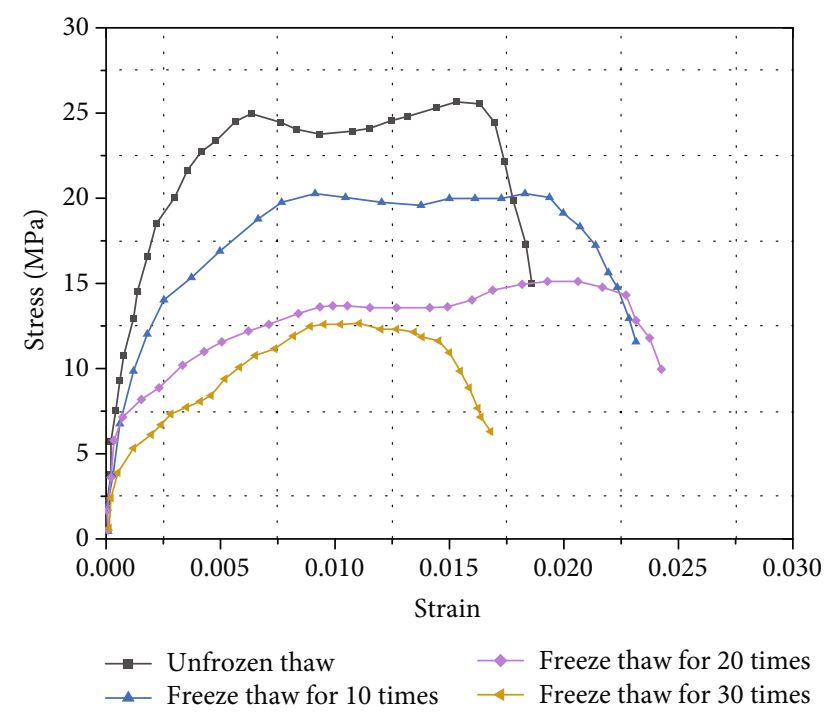

Figure 6: Average stress-strain curve of coal samples. water, the wave speed of the water-saturated rock sample is slightly larger than that of the dry rock sample. Figure 7 shows the histogram of the average wave velocity of coal samples versus the number of freeze-thaws. It can be found that the wave velocities of saturated coal samples after freeze-thaw cycles are all lower than those in the dry state. The wave velocity of saturated coal samples decreased by $10.03 \%$ after 10 freeze-thaw cycles, $12.16 \%$ after 20 cycles, and $33.46 \%$ after 30 freeze-thaw cycles.

In general, the damage of the material can indirectly reflect the internal crack expansion characteristics. To further evaluate the damage to coal samples by freeze-thaw cycles, damage factor $D$ was defined based on the variation of the wave velocity test values of the $P$-wave as follows:

$$
D=1-\left(\frac{V_{\mathrm{PF}}}{V_{p}}\right)^{2},
$$

where $V_{P}$ is the wave velocity value before the freeze-thaw cycle of the coal sample, and $V_{\mathrm{PF}}$ is the wave velocity value after the freeze-thaw cycle.

Soviet scholar L.M. Kachanov first proposed the concept of damage. Solid materials in an unsuitable environment or mechanical action (such as temperature, external loading, and corrosion), the internal microscopic cracks, microscopic hole generation, convergence, and expansion will cause local deterioration of the material, known as the material damage. The damage of the material will cause the material strength, stiffness, and toughness decline and shorten the service life. In order to give a proper description of the material microstructure change phenomenon, it is necessary to introduce the damage variable as an internal variable of the intrinsic structure relationship. Because the change of material structure is generally said to be irreversible, according to the thermodynamic point of view, the entropy of the material increases during the damage process, i.e., the damage occurs cumulatively, so the damage variable is not only an invisible internal variable but also an increasing quantity. Figure 8 shows the relationship between damage factors and freezethaw times of coal samples. As shown in Figure 8, the average values of damage factors for coal samples after $0,10,20$, and 30 freeze-thaw cycles were $0,0.21,0.24$, and 0.54 , respectively. The damage of the coal samples changed more after 30 freeze-thaw cycles, when the deterioration of coal 


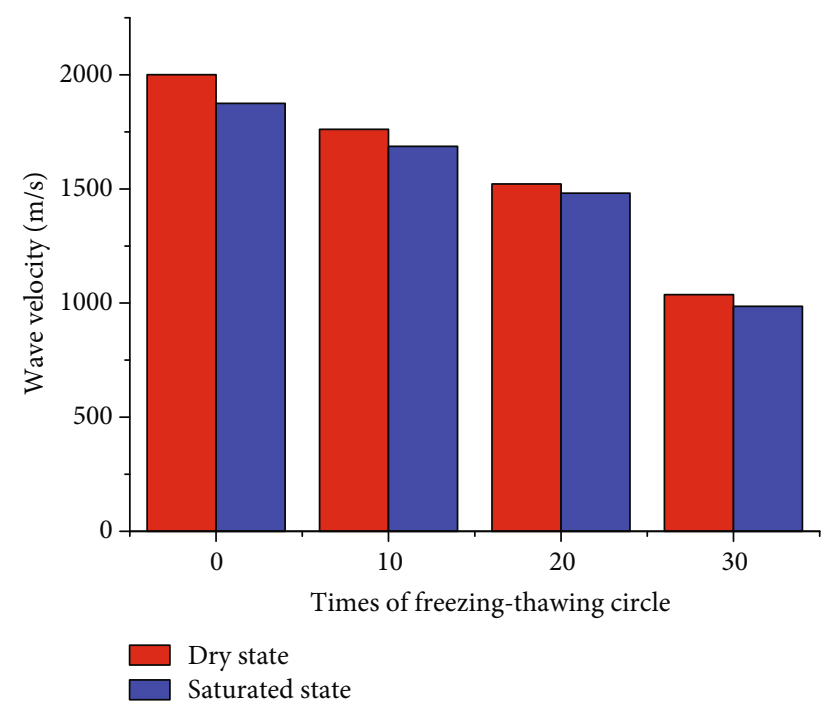

FIGURE 7: Histogram of the average wave velocity of coal samples versus the number of freeze-thaws.

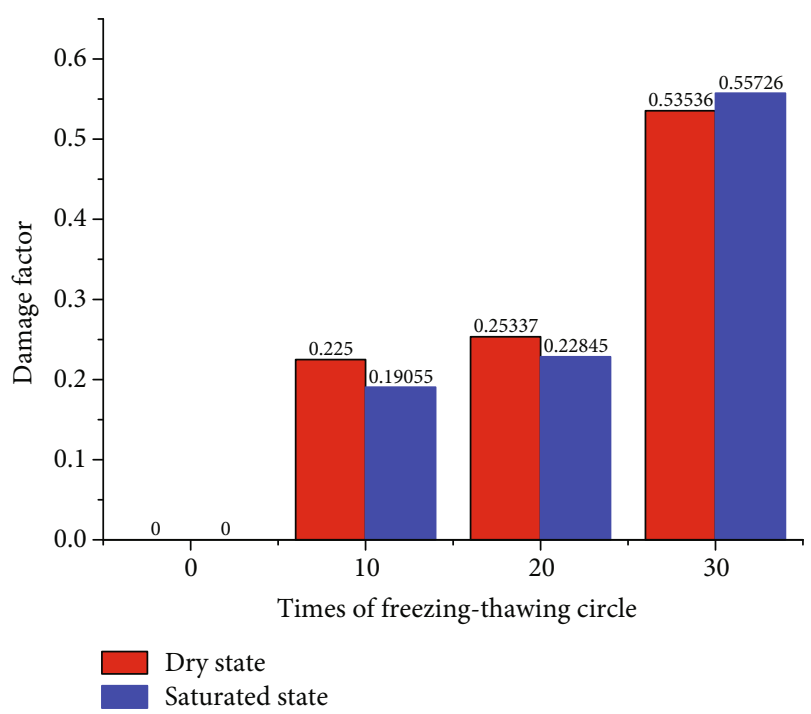

FIGURE 8: Relationship between damage factors and freeze-thaw times of coal samples.

samples was highest. Table 3 shows the change of porosity of coal samples tested by the NMR method, and it can be seen that the characteristics of the change of deterioration degree of coal samples reflected from the porosity are basically consistent with the damage factor.

3.2. Mechanical Properties of Coal after Freeze-Thaw Cycle under Dynamic Loading. In civil engineering construction, mining development, road construction, and other production fields, dynamic load is a factor that cannot be ignored. The physical and mechanical properties of slope rocks exposed to the air for a long time are changed after freezethaw damage. Due to the possible stress effect of the rock itself, it is also subjected to the impact of earthquake, blasting, landslide, etc. In-depth understanding of the impact
TABLE 3: Porosity of coal samples before and after freezing and thawing.

\begin{tabular}{lccc}
\hline Group & $\begin{array}{c}\text { Cycle } \\
\text { freeze-thaw } \\
\text { times }\end{array}$ & $\begin{array}{c}\text { Porosity before } \\
\text { freezing and thawing } \\
(\%)\end{array}$ & $\begin{array}{c}\text { Porosity after } \\
\text { freezing and } \\
\text { thawing (\%) }\end{array}$ \\
\hline $\begin{array}{l}\text { Group } \\
1\end{array}$ & 0 & 3.97 & 3.97 \\
$\begin{array}{l}\text { Group } \\
2\end{array}$ & 10 & 4.23 & 6.39 \\
$\begin{array}{l}\text { Group } \\
3\end{array}$ & 20 & 4.15 & 10.85 \\
Group & 30 & 4.35 & 12.93 \\
4 & & & \\
\hline
\end{tabular}

loads on freeze-thaw damaged rocks during the construction can avoid unnecessary losses. In order to ensure the safe production of open pit mines in cold regions, the study of their dynamical properties after freeze-thawing is particularly crucial.

Table 4 shows the mechanical parameters of coal samples after cyclic freezing and thawing. As shown in Figure 9, the elastic modulus of the coal sample after freeze-thawing decreases continuously with the increase of the number of freeze-thaw cycles, and its trend decreases approximately linearly. Moreover, the overall dispersion of the modulus of elasticity of the coal samples increases when the number of freeze-thaw cycles is 30 . The elastic modulus of coal samples varied from 1.2 to $4.5 \mathrm{GPa}$ within 30 freezethaw cycles. When the number of freeze-thaw cycles is lower than 20, the Poisson's ratio of coal samples decreases continuously with the increasing number of cycles. However, when the number of cycles continued to increase to 30 , the Poisson's ratio increased to some extent. When the number of freeze-thaw cycles reached 20, the Poisson's ratio of coal samples was the smallest. Figure 10 shows the relationship between dynamic compressive strength and freeze-thaw cycle times of coal samples after freeze-thaw. Dynamic compressive strength of the coal samples decreases after freezethaw cycles, and this trend is consistent with the quasistatic loading conditions.

The fitted functions between the mechanical parameters (modulus of elasticity, Poisson's ratio, and dynamic compressive strength) of the coal samples after freeze-thaw cycles and the number of cycles are as follows:

$$
\begin{gathered}
E=4.369 \times 0.978^{N}, R^{2}=0.83, \\
v=0.397-0.011 N+6.667 N^{2}+7.222, \quad R^{2}=0.85, \\
\sigma_{c t}=61.162 \times 0.951^{N}, \quad R^{2}=0.95 .
\end{gathered}
$$

Rocks are aggregates of mineral particles cemented together with various complex forms of cracks, holes, and other defects inside. During the freeze-thaw cycle, more holes and small cracks expand under the action of waterice phase change. At the same time, the mineral particles are deformed by the temperature stress, and the different 
TABLE 4: Mechanical parameters of coal samples after cyclic freezing and thawing.

\begin{tabular}{|c|c|c|c|c|c|c|}
\hline Cycle freeze-thaw times & Sample & Diameter (mm) & Height (mm) & Dynamic UCS (MPa) & Elastic modulus (GPa) & Poisson's ratio \\
\hline \multirow{3}{*}{0} & $\mathrm{~F} 1$ & 49.6 & 99.87 & 57.35 & 4.45 & 0.42 \\
\hline & F2 & 49.7 & 101.10 & 64.50 & 4.28 & 0.40 \\
\hline & F3 & 49.6 & 99.78 & 57.53 & 4.38 & 0.37 \\
\hline \multirow{3}{*}{10} & $\mathrm{~F} 4$ & 49.8 & 99.45 & 40.42 & 3.54 & 0.32 \\
\hline & F5 & 49.5 & 99.86 & 41.56 & 3.56 & 0.29 \\
\hline & F6 & 49.7 & 100.35 & 38.56 & 3.38 & 0.28 \\
\hline \multirow{3}{*}{20} & F7 & 49.6 & 99.87 & 27.65 & 2.91 & 0.25 \\
\hline & F8 & 49.8 & 98.78 & 24.68 & 2.85 & 0.27 \\
\hline & F9 & 49.6 & 98.69 & 18.65 & 2.70 & 0.24 \\
\hline \multirow{3}{*}{30} & F10 & 49.6 & 99.53 & 8.56 & 1.32 & 0.28 \\
\hline & F11 & 49.8 & 101.20 & 7.69 & 2.56 & 0.32 \\
\hline & F12 & 49.7 & 100.52 & 12.89 & 2.84 & 0.33 \\
\hline
\end{tabular}

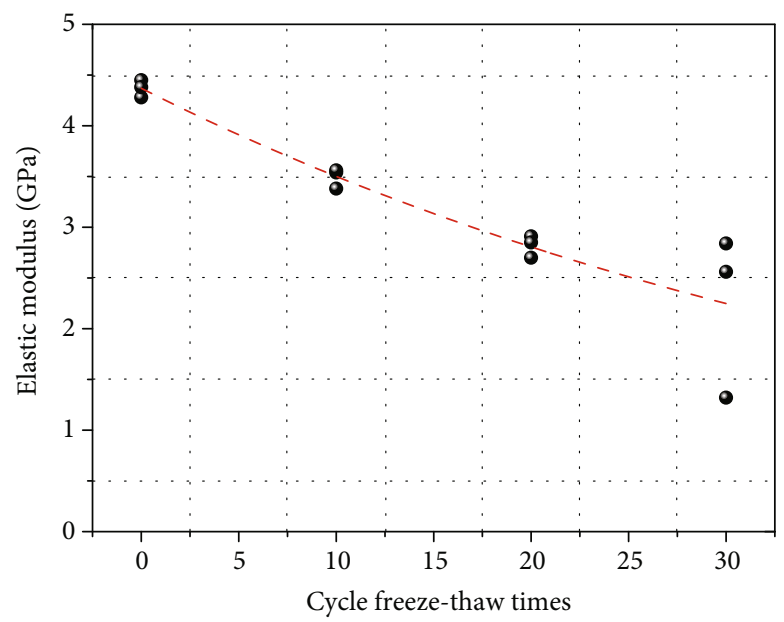

(a)

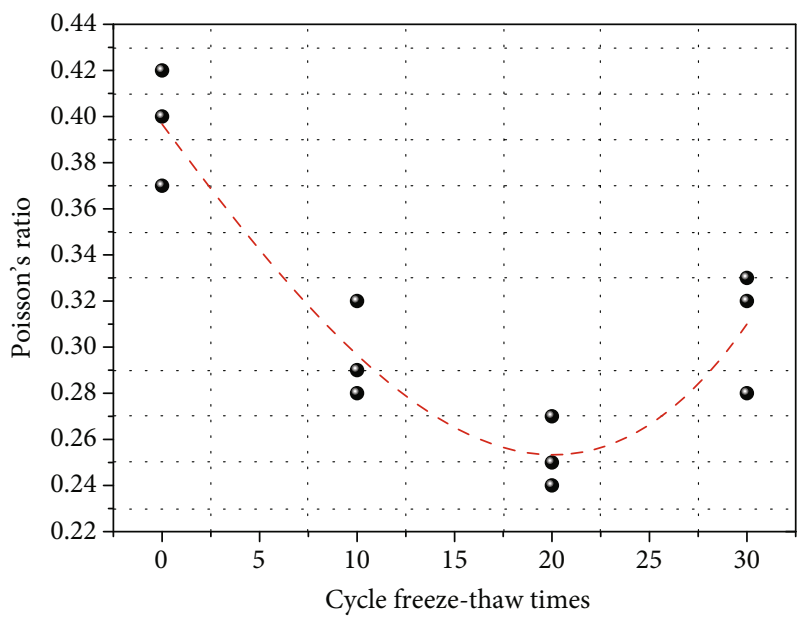

(b)

FIGURE 9: Relationship between deformation parameters and freeze-thaw cycles of coal samples. (a) Dynamic uniaxial compressive strength. (b) Poisson's ratio.

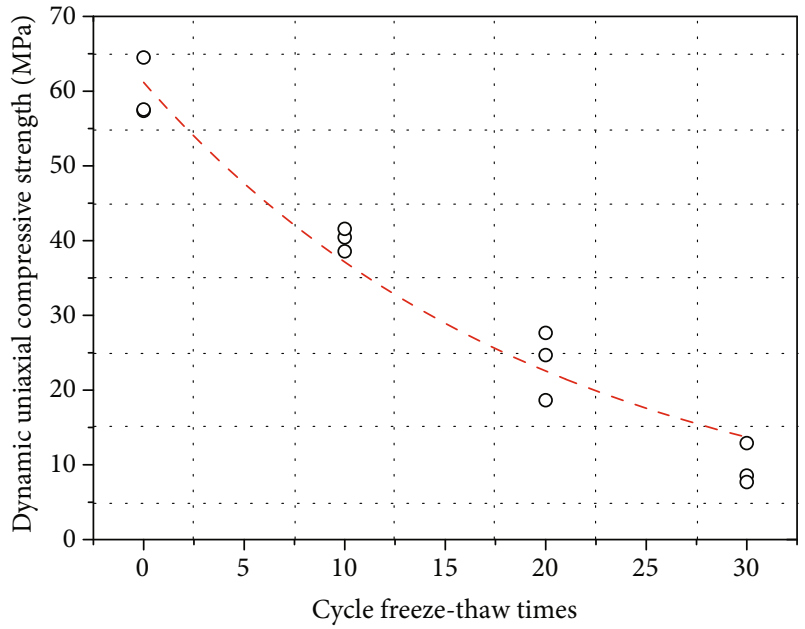

FIGURE 10: Relationship between dynamic UCS and freeze-thaw cycle times of coal samples after freeze-thaw. expansion coefficients lead to the uncoordinated deformation of different mineral particles. This leads to the expansion and accumulation of primary cracks, the initial state of the interparticle interface is destroyed, and even particle freeze-thaw damage. As a result, more debris is formed around the mineral particle interface, resulting in the loss of macroscopic freeze-thaw integrity of the rock, which is an important reason for freeze-thaw damage to occur in coal with low water content. The degree of crack extension and connectivity varies at different freeze-thaw stages. This leads to different degrees of degradation of physical and mechanical properties of coal samples after freeze-thaw cycles. The coal sample is saturated with water, and the microscopic observation of crumb-like material is more abundant. During the freeze-thaw process, the temperature stress is concentrated inside the rock, and the freeze-thaw cycle causes greater structural damage to the coal samples. This causes greater damage and destruction of coal samples, and therefore, this type of coal rock has poor freeze-thaw resistance. 


\section{Conclusions}

(a) With the increase of freeze-thawing times, the mass of both water-saturated and dried coal samples gradually decreased, and the decreasing trend was basically consistent. However, there is a slight difference in the degree of change between the two, which is due to the change in the degree of open fracture penetration caused by the formation and change of internal debris in the rock after different freeze-thawing times. Compared with the nonfreeze-thawed rock samples, the quality of the water-saturated rock samples decreased by $8.33 \%$ after 10 freeze-thaw cycles, $18.33 \%$ after 20 freezethaw cycles, and $33.33 \%$ after 30 freeze-thaw cycles

(b) The peak strength of the unfrozen-thawed specimens is the largest. With the increase of the number of freeze-thawing, the postpeak becomes gentler, and the specimens show ductile damage characteristics. The stress-strain curves of the specimens before and after freeze-thawing can be divided into four stages, i.e., compression-density stage, elastic stage, crack development stage, and damage stage. In particular, the compressive stage of freeze-thawed samples with 20 times of freeze-thawing increased significantly compared with those without freezethawing. This indicates that the first 20 freeze-thaw cycles led to the significant development of microfractures inside the specimens

(c) The wave velocities of saturated coal samples after freeze-thaw cycles are all lower than those in the dry state. The wave velocity of saturated coal samples decreased by $10.03 \%$ after 10 freeze-thaw cycles, $12.16 \%$ after 20 cycles, and $33.46 \%$ after 30 freezethaw cycles. The damage of the coal samples changed more after 30 freeze-thaw cycles, when the deterioration of the coal samples was the highest

(d) The elastic modulus of the coal sample after freezethawing decreases continuously with the increase of the number of freeze-thaw cycles, and its trend decreases approximately linearly. Moreover, the overall dispersion of the modulus of elasticity of the coal samples increases when the number of freeze-thaw cycles is 30 . The dynamic compressive strength of the coal samples decreases after freezethaw cycles, and this trend is consistent with the quasistatic loading conditions

\section{Data Availability}

Some or all data, models, or code that support the findings of this study are available from the corresponding author upon reasonable request.

\section{Conflicts of Interest}

The authors declare that they have no conflicts of interest.

\section{Acknowledgments}

This work was financially supported by the Fundamental Research Funds for the Universities of Henan Province (Grant no. NSFRF200332), Key Research and Development and Promotion of Special (Science and Technology) Project of Henan Province (nos. 212102310379 and 202102310542), National Natural Science Foundation of China (nos. 41907402 and 51604093), the research fund of Henan Key Laboratory for Green and Efficient Mining \& Comprehensive Utilization of Mineral Resources (Henan Polytechnic University) (no. KCF201804), the Key Scientific Research Project Fund of Colleges and Universities in Henan Province (no. 21A610005 and no. 20B440001), and the Doctoral Foundation of Henan Polytechnic University (no. B2019-22). All support is greatly appreciated.

\section{References}

[1] H. Xie, Y. Ju, M. Gao et al., "Theories and technologies for insitu fluidized mining of deep underground coal resources," Journal of China Coal Society, vol. 43, no. 5, pp. 1210-1219, 2018.

[2] W. Shen, G. Shi, Y. Wang, J. Bai, R. Zhang, and X. Wang, "Tomography of the dynamic stress coefficient for stress wave prediction in sedimentary rock layer under the mining additional stress," International Journal of Mining Science and Technology, vol. 31, no. 4, pp. 653-663, 2021.

[3] S. Gong, L. Zhou, Z. Wang, and W. Wang, "Effect of bedding structure on the energy dissipation characteristics of dynamic tensile fracture for water-saturated coal," Geofluids, vol. 2021, Article ID 5592672, 10 pages, 2021.

[4] N. Kivekäs, J. Sun, M. Zhan et al., "Long term particle size distribution measurements at Mount Waliguan, a high-altitude site in inland China," Atmospheric Chemistry and Physics, vol. 9, no. 15, pp. 5461-5474, 2009.

[5] S. Gong, "Investigation of tensile and fracture mechanical properties of bituminous coal at different strain rates," Journal of Materials Research and Technology, vol. 15, pp. 834-845, 2021.

[6] Y. L. Duan, G. Bellis, L. Li et al., "Potential vectors of bluetongue virus in high altitude areas of Yunnan Province, China," Parasites \& Vectors, vol. 12, no. 1, pp. 1-11, 2019.

[7] Y. Wang, Y. F. Yi, C. H. Li, and J. Q. Han, "Anisotropic fracture and energy characteristics of a Tibet marble exposed to multi-level constant-amplitude (MLCA) cyclic loads: a labscale testing," Engineering Fracture Mechanics, vol. 244, p. 107550, 2021.

[8] Y. Wang, B. Zhang, B. Li, and C. H. Li, "A strain-based fatigue damage model for naturally fractured marble subjected to freeze-thaw and uniaxial cyclic loads," International Journal of Damage Mechanics, vol. 10567895211021629, p. 105678952110216, 2021.

[9] G. Liu, D. Song, Z. Chen, and J. W. Yang, "Dynamic response characteristics and failure mechanism of coal slopes with weak intercalated layers under blasting loads," Advances in Civil Engineering, vol. 2020, 18 pages, 2020.

[10] Z. Li, S. Yu, W. Zhu et al., "Dynamic loading induced by the instability of voussoir beam structure during mining below the slope," International Journal of Rock Mechanics and Mining Sciences, vol. 132, p. 104343, 2020. 
[11] D. Deb, K. N. R. Kaushik, B. H. Choi, C. H. Ryu, Y. B. Jung, and C. Sunwoo, "Stability assessment of a pit slope under blast loading: a case study of Pasir coal mine," Geotechnical and Geological Engineering, vol. 29, no. 4, pp. 419-429, 2011.

[12] G. Yang, Y. Shen, H. Jia, R. Wei, H. Zhang, and H. Liu, "Research progress and tendency in characteristics of multiscale damage mechanics of rock under freezing-thawing," Chinese Journal of Rock Mechanics and Engineering, vol. 37, no. 3, pp. 545-563, 2017.

[13] S. Xu, N. Li, X. Wang et al., "Damage test and degradation model of saturated sandstone due to cyclic freezing and thawing of rock slopes of open-pit coal mine," Chinese Journal of Rock Mechanics and Engineering, vol. 35, no. 12, pp. 25612571, 2016.

[14] L. Wen, X. Li, H. Tang, and L. Weng, "Study of physicomechanical characteristics of rock under different frozenthawed circle temperature range and its engineering application," Engineering Mechanics, vol. 34, no. 5, pp. 247-256, 2017.

[15] İ. İnce and M. Fener, "A prediction model for uniaxial compressive strength of deteriorated pyroclastic rocks due to freeze-thaw cycle," Journal of African Earth Sciences, vol. 120, pp. 134-140, 2016.

[16] M. Fener and İ. İnce, "Effects of the freeze-thaw (F-T) cycle on the andesitic rocks (Sille- Konya/Turkey) used in construction building," Journal of African Earth Sciences, vol. 109, pp. 96106, 2015.

[17] G. Khanlari and Y. Abdilor, "Influence of wet-dry, freezethaw, and heat-cool cycles on the physical and mechanical properties of Upper Red sandstones in Central Iran," Bulletin of Engineering Geology and the Environment, vol. 74, no. 4, pp. 1287-1300, 2015.

[18] J. Park, C. U. Hyun, and H. D. Park, "Changes in microstructure and physical properties of rocks caused by artificial freeze-thaw action," Bulletin of Engineering Geology and the Environment, vol. 74, no. 2, pp. 555-565, 2015.

[19] P. Wang, J. Xu, S. Liu, H. Wang, and S. Liu, "Static and dynamic mechanical properties of sedimentary rock after freeze-thaw or thermal shock weathering," Engineering Geology, vol. 210, pp. 148-157, 2016.

[20] P. Wang, J. Xu, S. Liu, S. Liu, and H. Wang, "A prediction model for the dynamic mechanical degradation of sedimentary rock after a long-term freeze-thaw weathering: considering the strain-rate effect," Cold Regions Science and Technology, vol. 131, pp. 16-23, 2016.

[21] K. P. Zhou, B. Li, J. L. Li, H. W. Deng, and F. Bin, "Microscopic damage and dynamic mechanical properties of rock under freeze-thaw environment," Transactions of Nonferrous Metals Society of China, vol. 25, no. 4, pp. 1254-1261, 2015.

[22] L. Wen, X. Li, Y. Yin, and L. Gao, "Study of physicomechanical properties of granite porphyry and limestone in slopes of open-pit metal mine under freezing-thawing cycles and their application," Journal of Glaciology and Geocryology, vol. 36, no. 3, pp. 632-639, 2014. 